\title{
The Material Foundations of Modern Scientific and Technological Advances
}

\author{
George E. Pake \\ Group Vice President, Corporate Research Group, Xerox Corporation
}

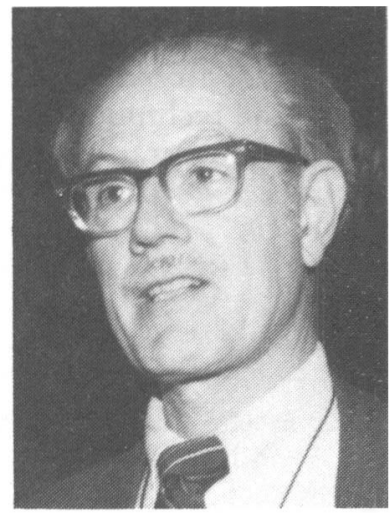

The following is a transcript of Dr. Pake's address presented at the 1985 MRS Spring Meeting in San Francisco.

$t$ is a pleasure to be with you this evening. In my distant past as a once active researcher, it seems likely that my research interests would have impelled me to be active in the Materials Research Society, had it been flourishing in those days. But today, I find myself with responsibility for approximately 1,000 research personnel distributed among three Xerox research centers. The Webster Research Center, in Webster, New York, which is located in the Joseph C. Wilson Center for Technology, was historically the first Xerox Research Center. As you might expect, its focus has been on the xerographic imaging and marking process. With its theme of imaging and marking, many of its professionals are physicists or chemists, although there are also some engineers. And materials research is a very important component of its activities.

The second research center, historically, is the Palo Alto Research Center founded in 1970. Its focus is on digital science and technology, along with an important component of materials research related to electronics and electrooptics. Our third and newest research center is in Mississauga, Ontario, just a few kilometers west of Toronto. The theme of this Xerox Research Centre of Canada is materials science and technology. The materials with which XRCC concerns itself are those important to all of our business: copiers, duplicators, and printers, including photoreceptors, dry toners, inks, and paper.

I suspect that there is very little I can tell this group about the materials research foundation upon which rest the many technological advances which enable the functioning of our modern society. Perhaps the most celebrated of these advances are those relating to integrated circuits. Memory chips and microprocessors incorporating LSI or VLSI technology are becoming ubiquitous. New systems technology is now enabled by these advances. All of this goes back to the transistor and its invention as a replacement for the vacuum tube (or for the valve, if you prefer).

The progression from gas envelopes to solid-state devices has proceeded apace. Gas lasers are now finding themselves candidates for being supplanted by solid-state laser diodes in many applications. There is at least the prospect that some kind of solid-state display technology will supplant the CRT, but for most applications this transition has proved difficult and has been slow to take place. That CRT s are too bulky, too expensive to build, and too extravagant in use of power have all been evident for decades, but the ideal low-cost, rapid-response, low-power, high resolution, solid-state flat panel display remains as a challenge to materials scientists and technologists.

In Xerox, we have considerable optimism that we can, for our laser xerographic printers, replace rotating polygons for laser scanning with solid-state devices having no moving parts. In general, these transitions to high-reliability, lower-cost solid-state devices are enabled by the accumulating advances from materials research.

Futurists make a big point of the fact that we are entering the information age. There is much discussion of the importance of software and of knowledge-based systems. All of this emphasis-and our growing U.S. proficiency in information science, and cognitive processes - is, 1 believe, the basis for continuing U.S. technological leadership in the next two or three decades. The focus on ideas and on systems that extend and employ human expertise is made possible by the advances in materials science and technology generated through materials research.

From a broad perspective, materials research has enabled modern solid-state microelectronics. Modern electronics, in turn, advances almost every field of human endeavor. In a commercial sense, consumer electronics and communications depend critically on the high function, durability, reliability, and low cost of solid-state electronics. Automobiles-which were for so many years simply large aggregations of low technology-have suddenly, with concerns for fuel economy and for prevention of pollution, become dependent on microprocessor control, and the entire au to is now quite sophisticated technologically. Even washing machines and dishwashers are now microprocessor controlled.

But there are other more widely extending applications. Solid-state electronic instrumentation is important to every quantitative function in our commercial world. Banking transactions, petroleum exploration, medical instrumentation are just a few examples. And the petroleum and 
medical examples merely hint at the dependence of other sciences upon modern electronic instrumentation. Analytical chemistry, biology, earth and planetary science, and high-energy physics are all progressing rapidly to new levels of understanding enabled in large part by modern electronic instrumentation and also by the properties and capabilities of new materials resulting from materials research.

There is one of these areas of science about which I want say a few words, that is, particle physics or high-energy physics. As some of you may be aware, I accepted appointment last year to the Board of Overseers for the projected new particle accelerator, the Super Conducting Super Collider-generally known as the SSC. The community of high-energy physicists has concluded, with a consensus and internal discipline not always to be found within communities of research scientists, that the most important next requirement to advance elementary particle physics is a 20 trillion electron volt proton synchrotron, constructed of two adjacent rings in the same large diameter tunnel. The tunnel will be approximately 100 kilometers in circumference or about 20 miles in diameter. (See Figure 1).

Our knowledge of the elementary particles constituting matter has proceeded to the point where high-energy particle physicists require center-of-mass energies of 20 $\mathrm{TeV}$ to effect the close interaction of the constituent quarks within colliding protons in order to ferret out the remaining pieces of the puzzles relating to particle species and the strong force. Our current experience with large proton synch rotrons provides a useful base from which to work in planning to achieve these desired 20-TeV energies. Already functioning since 1983 at Fermilab in Batavia, Illinois, is the Tevatron (Figure 2). It provides $1 \mathrm{TeV}$ reliably using 1,000 large superconducting magnets. The main ring is 6.3 kilometers in circumference, and the machine is being upgraded for operation as a proton-antiproton collider, 1 TeV on $1 \mathrm{TeV}$.

The European CERN laboratory in Geneva, is home to the Super Proton Synchrotron with a total collison energy of $640 \mathrm{GeV}$ (Figure 3). The main ring is 7 kilometers in circumference, buried underground. This is the world's largest energy collider now in operation.

A 20-mile-diameter particle accelerator having 5,000 or more superconducting magnets in a subterranean tunnel will, of course, cost much money to construct and to

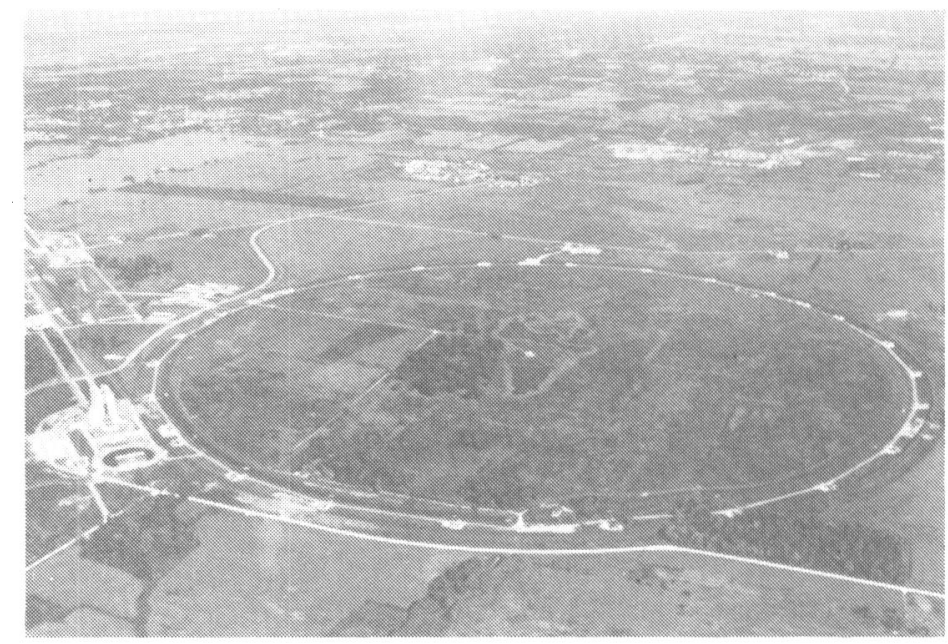

Figure 2

Aerial view of the Fermi National Accelerator (Fermilab) at Batavia, Illinois. The main ring of this fixed-target proton synchrotron is 6.3 kilometers in circumference. It is presently being upgraded for operation as a proton-antiproton collider with a total collison energy of $2 \mathrm{TeV}$. (Courtesy of Fermi National Accelerator Laboratory.)

operate. In order to estimate the costs and schedule, the Department of Energy commissioned the Universities Research Association (URA), a consortium of 56 U.S. universities, to conduct a study in the summer of 1984 . The major technological design issue has to do with the design of the superconducting magnets to bend the high-energy proton beam into its circular orbit (See Figure 4). The initial SSC design study concluded that the total accelerator cost would be relatively independent of the magnet design selected (within 10\%) at about $\$ 2.8$ billion. This estimate does not cover site acquisition cost, nor cost of measuring and detection instrumentation.

URA has established a Board of Overseers to watch over the SSC project. The chairman is Prof. Boyce McDaniel of Cornell University, and as I said, I happen to be a member of that board. The URA and the DOE are establishing site selection criteria. A Central Design Group under Dr. Maury Tigner of Cornell is in residence at Lawrence Berkeley Laboratory pursing magnet design and other design issues, under research contract support from the DOE.

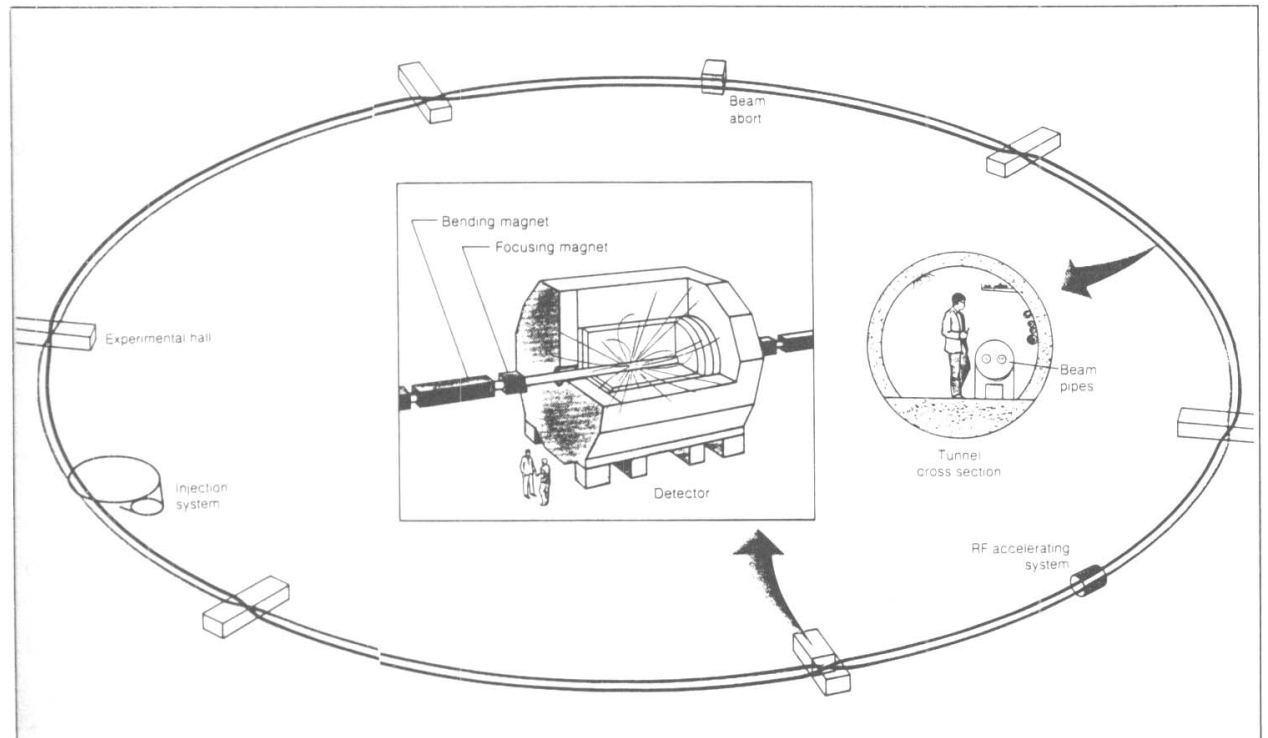

Figure 1

Schematic of possible payout for the SSC, which would be roughly 100 kilometers in circumference. The injection system is drawn to scale; the six experimental halls and other components on the main ring are not. In the detail of the detector, the beam pipe and its magnets are shown oversized. 


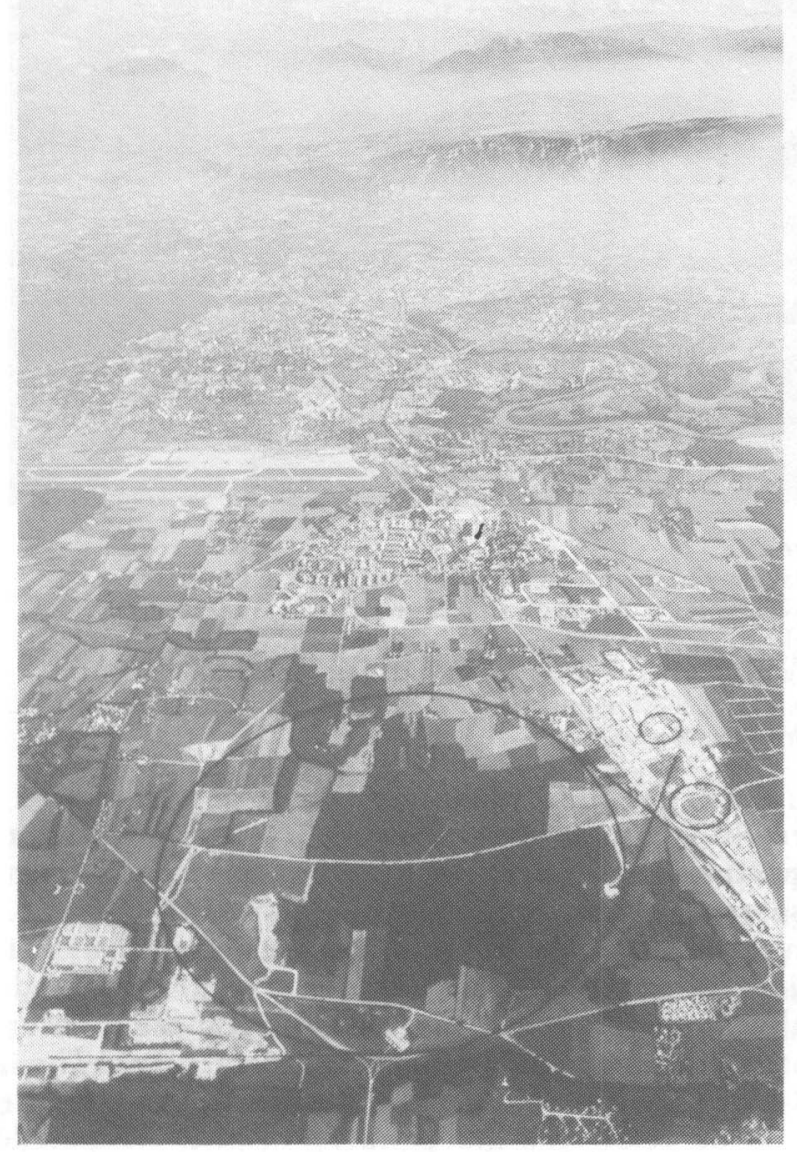

Figure 3

Aerial view of CERN in Geneva, showing the location of the Super Proton Synchrotron, a proton-antiproton collider with a total collison energy of $640 \mathrm{GeV}$. It is the world's most powerful collider. The main ring, which is 7 kilometers in circumference, is buried underground. The land above it is undisturbed and retains its traditional use for farming. (Courtesy of CERN.)

Notwithstanding all of this activity, the SSC still does not have official DOE approval, much less authorization and funding by Congress. The SSC represents quite clearly a major decision and potential commitment for U.S. science. Some of my colleagues in the scientific community have substantial reservations about the wisdom and desirability of the United States going forward with SSC. Doubtless there are a number of people at this MRS meeting who hold such skepticism. With this state of affairs, I thought it might be worthwhile for me to describe to you why I accepted appointment to the Board of Overseers, and why I strongly support the proposition that the United States should build the SSC.

My own research interests in the couple of decades during which I was an active researcher were condensed matter physics and chemical physics. Now, I hold responsibility for the entire research program of a business corporation which sustains itself and its stockholders by surveying technological applications to the business office. In view of my own vested interests in condensed matter physics and in commercialization of technology, you may well ask why I support a taxpayer subvention of $\$ 3$ billion to construct the world's largest most powerful particle accelerator.

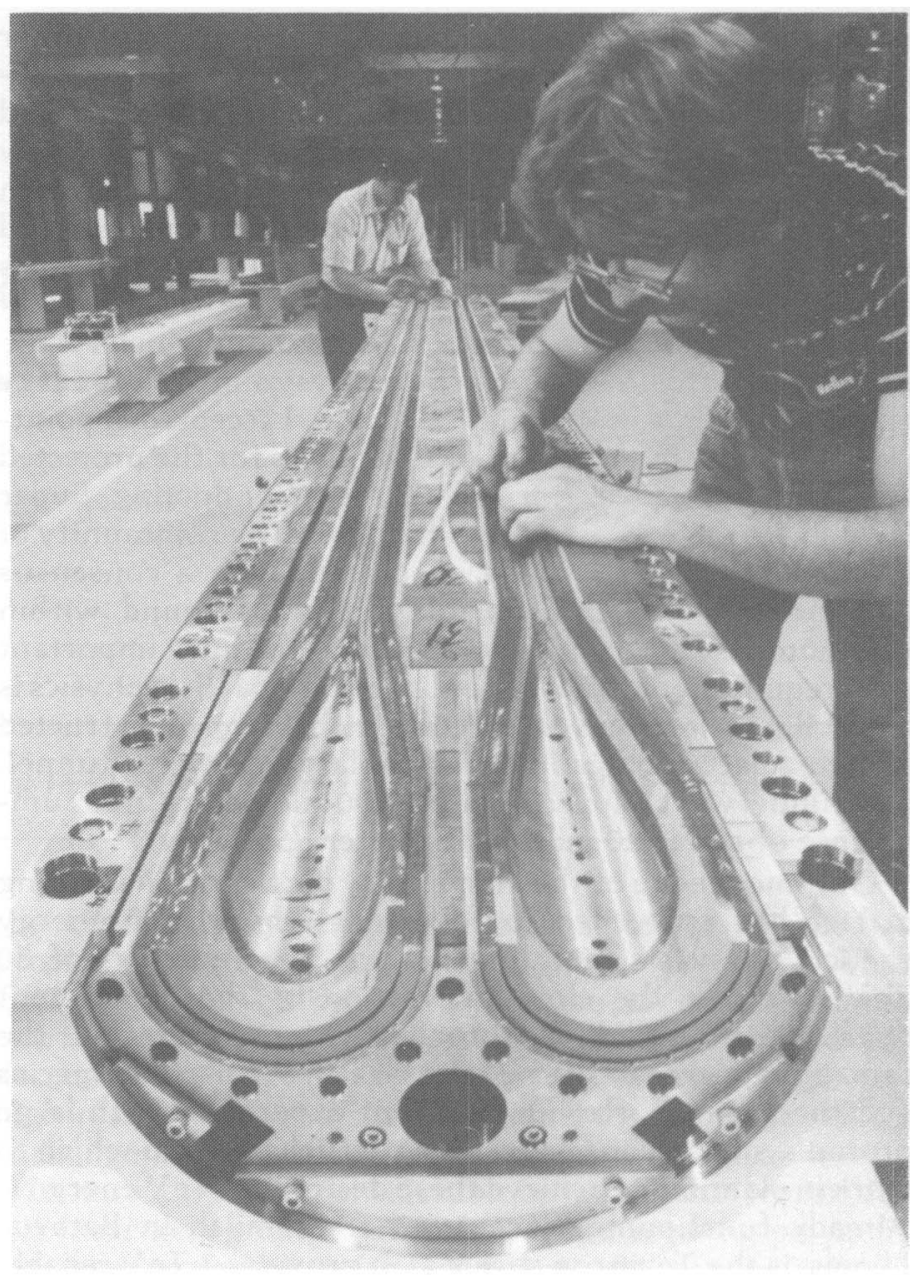

Figure 4

A dual-beam-line superconducting SSC model magnet in the assembly stage. Its operation requires cooling with liquid helium to a temperature a few degrees above absolute zero. /Courtesy of Brookhaven National Laboratory.

Before I offer my rationale, let me concede some points: Although the SSC is intended to improve our most fundamental understanding of the ultimate composition of matter, I do not contend that the SSC will directly produce substantial advances for condensed matter physics. Although there will be substantial technological and engineering fallout from the SSC project-for example, in advancing superconducting magnet technology - these are by-products and do not in themselves constitute adequate justification for the SSC.

\section{"Nothing is more pragmatic than the broadest and deepest knowledge base mankind can attain."}

Why do I favor the major investment - this gargantuan particle physicists' "boondoggle" or whatever worse name it s critics may give it? How can a hard-bitten industrialist, with all his pragmatic concerns, be an outspoken advocate of such a large and costly project that has so little direct 
economically tangible return? It is simple: For the nearterm and long-range future vigor and benefit of the U.S. industrial and even military economy, the most pragmatic posture I can imagine is one that opts by overt choice for the most advanced knowledge and deepest understanding. For the United States instead to deliberately choose a "metoo" or "also-ran" research science status is to opt for ignorance rather than knowledge. Nothing is more pragmatic than the broadest and deepest knowledge base mankind can attain. And I am just chauvinistic enough to believe that the welfare and economic vigor of the United States is best assured if we lead the world in advancing knowledge and in developing that broad, deep knowledge base.

The imperatives of science-and the imperatives even of the academy in the broad sustained quest for knowledgeare very nearly congruent with the requirements for industrial technological leadership. Nothing is more pragmatic than technological leadership, which while it requires many ingredients, rests primarily, I believe, on worldleading science and on our cadre of the world's best, brightest, and most effective research practitioners.

For any part of science where we have world leadership, or where it is within our grasp, I would never run the risks entailed in deliberately opting to be an "also-ran." I believe that, in some deep sense, it is un-American to choose to be one of the world's scientific "also-rans." In respect to world leadership in science, we condemn this nation to protracted miseries if we opt for ignorance. I believe this deeply in a philosophical sense, but it is quite evidently also for me a highly pragmatic point

Some peole may say "Well, okay. But in particle physics! And to the tune of $\$ 3$ billion?" My answer is "Yes, and even to the tune of $\$ 3$ billion." I know that $\$ 3$ billion is a great deal of money, but it is comparable to the cost of a modern aircraft carrier - maybe less if you count it complement of jet planes. I believe that, on military grounds alone, the SSC buys the nation more security than an aircraft carrier does. And who among us would miss one fewer nuclear powered aircraft carrier? I'm not sure that even the Admirals would miss just one fewer carrier. What does the SSC buy in a military sense? First, it keeps us sharp in certain highly skilled craftsmanship and technological domains. Perhaps most important, it helps us to build and sustain a cadre of very bright scientists accustomed to world-class technical activities and aiming at world leadership. Recall the critical roles filled in World War II by our labora tory and theoretical scientists from even the most esoteric of scientific pursuits. The SCC project will build a world-leading, vigorous human technical capability.

My comparison with an aircraft carrier can be critized because Congress will not actually make the decision on the SSC by asking itself, "Would we really rather spend the money on a nuclear carrier and a few dozen jet fighters?" Nor will it say, lets have SSC but, to pay for it, we'll simply knock $\$ 3$ billion out of the Defense Department budget. These are valid criticisms.

The foregoing criticism brings to mind another objection I have heard from some scientists about the SSC. They say it will over the years place too big a lien on the annual budget for science and research. There is only a very limited sense in which that comment has any validity: it will surely place an annual lien on the DOE budget for research. But in the larger sense, the argument is wrong, because there is no U.S. science budget considered and enacted as a whole. There are the respective agency budgets, many of which have an identifiable science component. After the fact, analysts can look over the total federal budget and aggregate these components into the total number of dollars expended for science. Congress however does not arrive at the constituent elements of the so-called science budget by using this aggregating procedure.

Still another criticism I hear about the SSC expenditure runs as follows: $\$ 3$ billion construction and $\$ X$ hundred million a year for operation could better be spent on cancer research or, perhaps from this group, on materials research.

\section{"Nothing is more pragmatic than technological leadership, which while it requires many ingredients, rests primarily on world-leading science and on our cadre of the world's best, brightest, and most effective research practitioners."}

This kind of argument is, I feel, somewhat specious. It is really a version of the so-called principle that if something is good, more of it is better - surely a flaky principle, at best. There are at least hypothetical ways in which the criticism could have validity. If the further advance of cancer research or of materials science depended upon one major, identifiable $\$ 3$ billion next step, then we could argue the relative merits of world leadership in particle physics, of advancing cancer research, or of the technological benefits from this one major leap forward in materials research.

But materials research is not of such a nature that a single $\$ 3$ billion project determines its future advance. I am willing to wager that, if materials research were such an in trinsic nature that its future can depend on a single major facility, most of the people in this room would not have made the career choices that now lead then to be members of the Materials Research Society.

In my experience with budgets, whether as a physics department chairman, a university executive vice chancellor, an industrial research director, or now as a vice president for corporate research, the issue is never whether a given activity could use a lot more budget beneficially. Instead, each proposed activity must meet certain tests of relative importance to the task or domain in question, and tests of whether the people proposing it have the requisite skills and a credible track record. From my perspective, the particle physicists of the United States pass these tests with flying colors. We need to support particle physicists in their efforts to provide the United States with world leadership in this most fundamental area of modern physics.

Furthermore, to an important degree, the proposal for the Superconducting Super Collider is the result of the activities of the members of the Materials Research Society: the SSC project is only possible because of advances in superconducting materials which enable the magnets, in the understanding of critical materials elements of the particle detectors, and of course in the transistors of the in tegrated circuits that perform the data measurements and analyses. 
Seriously, I don't really hold you people responsible for the SSC proposal. But I do urge you to support the bold U.S. practitioners of our most fundamental branch of physics as they take the steps to lead the world in this high scientific calling.

\section{"We need to support particle physicists in their efforts to provide the United States with world leadership in this fundamental area of modern physics."}

\begin{abstract}
QUESTION: What choices have already been made that have ruled out other alternatives for big science in order to pursue the advanced knowledge in this particular area?
\end{abstract}

ANSWER: First of all, I probably cannot enumerate all the various accelerator proposals of one kind or a nother that have come forward, but the high-energy physics community, which has emplaced a thing called the High Energy Physics Advisory Panel, has looked at this question, and decided that there is only one thing that they urge as a next step: the SSC. That community has been very good over the years. It has closed on many accelerators. It's taken a very tough posture with respect to keeping the community researching at the frontier. It made some very hard decisions, and I think it's quite unique that there is almost no other community of research scientists that can decide what should be the next thing for its science and what other things may have to be put aside.

QUESTION: You mentioned that you want to answer the ultimate question: the fundamental behavior of nature. How do we know that after we reach there, we will not find more mystery that will require higher energy? How do we calculate the ultimate limit beyond which we may not go before we understand all that?

ANSWER: It is quite likely we will only arrive at some point where we will have still further questions if we advance in this field using this new machine. The quest is to try to unify the theoretical comprehension of the various forces. Already the electro-weak forces have been, in some sense, unified by the theorists. If we come close to that with this machine, we will not have erased or eliminated further curiosities. However, we will have made a very fundamental advance. There is a debatable point about whether the United States should wait and try to involve other nations to help them share the cost. That's worth debating and thinking about. High-energy physics has been quite remarkable for the extent to which international cooperative research has taken place. We have had scientists go to work at European laboratories and in Russian laboratories. There is a fair a mount of exchange back and forth. We see very few other domains in which there's that kind of international cooperation. I don't want to speculate on what happens after the $\$ 3$ billion SSC gets built, but I certainly will concede that there will be many unanswered fundamental questions. Science would be pretty disappointing if we got all these fundamental questions answered.

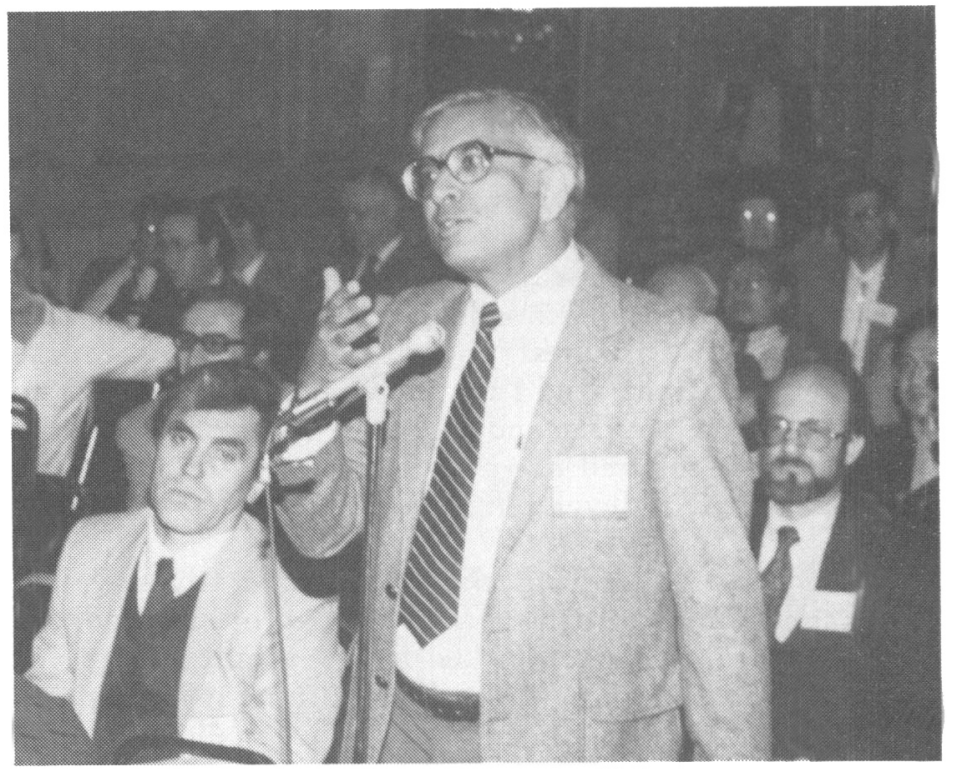

QUESTION: The sites committee has recently made a series of recommendations on upgrading existing facilities and creating new neutron facilities, as well as some new synchrotron sources, which would be about $\$ 1$ billion total over an eight-year period for major facilities. Now you are telling us that the SSC is $\$ 3$ billion over about a 10-year period. How does one balance out these different areas and different directions within the major facility funding issues?

ANSWER: There truly is and will be competition for funding between those kinds of recommendations. But the distinction that the materials science, solid-state physics, or whatever portion you choose to express as your domain if interest does not hinge critically on that particular set of expenditures or facilities for its future advance. People will continue to move forward with existing facilities. I contend that, very great advances toward fundamental questions concerning particle physics or high-energy physics cannot be made without some machine in this energy domain. The distinction is that these facilities, while important to materials or solid-state science - the ones that were pushed for by the sites report - are not in themselves absolutely indispensable to further progress in the field.

QUESTION: When you play a chip like this for funding, you can only play it once. Is this the most advanced blue sky, high-energy thing? Are you sure you're not going to turn around and build another one in six years?

ANSWER: As best I can understand from being on the SSC Board of Overseers, it is the boldest step that can be taken to advance the field that has any amount of assurance of being successful. That's based upon the positive experience with the superconducting magnets in the Trevatron at Fermilab. It would be hard to imagine really a larger step that might compete with this. There are some secondary or short-fall types of compromises that have been discussed. For instance, there is a plan to build an even larger accelerator at Lausanne. And there is a proposal for us to put a machine like this in their tunnel when they build it. But that turns out to be almost or very nearly as costly, without providing the real breakthrough in energy that is needed to get into this domain to understand the whole business about quarks and gluons, etc. There is almost no other really bold step that you can take which has any assurance of being feasible or technically implementable. 